\title{
CDISC SEND Fetal Pathology Findings Test Name Terminology
}

National Cancer Institute

\section{Source}

National Cancer Institute. CDISC SEND Fetal Pathology Findings Test Name

Terminology. NCI Thesaurus. Code C124315.

Terminology associated with the fetal pathology findings test name codelist of the Clinical Data Interchange Standards Consortium (CDISC) Standard for the Exchange of Non-clinical data (SEND). 